\title{
The Students Views of Nanotechnology and Its Application: A Case of Egypt Agricultural Secondary Schools
}

\author{
Rafeek Elmeanawy ${ }^{1}$, Amany Elgendy ${ }^{2}$ Dr. Wafaa El- Zontahy ${ }^{3}$ \\ ${ }^{1}$ Demonstrator at Department of Curricula and Teaching Methods, Majoring in Agricultural Sciences, Faculty of Education \\ Tanta University. Egypt \\ Rafeek.elmeanawy@edu.tanta.edu.com \\ ${ }^{2}$ MSc at Department of the Curricula and Teaching Methods, Majoring in Science, Faculty of Education, \\ Tanta University. Egypt. \\ pg_84815@edu.tanta.edu.eg \\ ${ }^{3}$ Lecturer at Department of Curricula and Teaching Methods, Majoring in Science, Faculty of Education \\ Tanta University. Egypt. \\ Wafaa.elmenofi@edu.tanta.edu.eg
}

\begin{abstract}
The current study aimed to determine the extent of knowledge and attitudes of agricultural secondary school students about nanotechnology and its applications in agriculture and food in Egypt. A diagnostic interview form was used to measure the participants' knowledge of nanotechnology, and the attitude scale toward nanotechnology was used to determine their attitudes, and it was applied to a sample of 105 students. The results showed the low knowledge of the sample students about nanotechnology as well as their attitudes towards it. As there are also no differences between the specialization of agricultural mechanization, laboratory custodians, and food processing, as there is no difference between boys and girls, and the results showed a positive relationship between students' nano-knowledge and their attitudes towards it. The study recommended the necessity of including the concepts and applications of nanotechnology in the curricula of agricultural secondary schools, through the development of existing curricula, enrichment programs, or completely new curricula.
\end{abstract}

Keywords: Nano-knowledge, Attitudes, Agricultural Secondary Schools' Students

\section{Introduction}

The world is witnessing wide and rapid progress today in several areas, most notably nanotechnology (NT) and its applications, which included all branches of agricultural sciences. since graduates of agricultural high schools will join the labor market directly. and they will naturally be exposed to Nano scale tools and products in the fields of their specialties. The rapid development and impact of Nano science and nanotechnology on economy has led policy makers and educators to focus on nanotechnology education [19]. The importance of nanotechnology was recognized worldwide between 2001 and 2004, with more than sixty countries establishing programs at the national level in the field of nanotechnology [22]. Regardless of whether nanotechnology is included in the nation's development goals, nanotechnology products will flood the markets internationally. The public's attitude towards nanotechnology products will depend on their awareness of this technology and their perception of how it affects their lives [20].

The potential impact of Nano science and nanotechnology has made these areas a critical part of everyday life, to improve the quality of life. A positive economic return is expected in the form of benefits such as business creation and jobs, enhanced competitiveness and trade while supporting growth and sustainability.

Several countries and educational systems already have nanotechnology activities and programs within their academic programs [26]. Therefore, this topic should be discussed by all stakeholders in all communities.

It has repeatedly been suggested that NT education be provided at various levels. A number of stakeholders, including governments and public administrations, business and commerce, community organizations, Nano scientists and engineers, technology and science 
educators, and sociologists, have voiced these demands [13]. The most prominent fear is the looming shortage of Nano scale-focused researchers, engineers, and other workers. However, in many cases, the necessity for NT education has been expressed.

Since Egypt is primarily an agricultural country, continuously reviewing agricultural education curricula in the light of the new developments is necessary to modify its objectives in line with the requirements of the labor market and the needs of society. Thus, reflecting on its curricula and programs to meet these requirements and needs. Many studies recommend the need to integrate nanotechnology into education such as:[11];[13];[15];[19];[20];[25].

It is clear from the above that many educators and academics indicate the importance of awareness of societies and students about nanotechnology.

So, this study was conducted in order to determine the extent of knowledge and attitudes of agricultural secondary school students about nanotechnology and its applications. And From the main objective, the following sub-questions are derived:

1) what is the degree of knowledge of agricultural secondary school students about nanotechnology and its applications in agriculture and foods in Egypt?

2) what is the degree of attitudes of agricultural secondary school students about nanotechnology and its applications in agriculture and foods in Egypt?

3) is there a correlation between agricultural secondary school students' knowledge of nanotechnology and its applications in agriculture and food and their attitudes towards it?

\section{Literature review:}

The continuous increase in innovative applications of nanomaterial's has been accompanied by concerns about their potential health and environmental impacts due to their unique and somewhat unpredictable properties. Nanotechnology is a rapidly developing science of understanding and controlling matter that has profound impact on many different fields due to its interdisciplinary nature and by providing new opportunities in the Nano scale dimension (1,000 times smaller than a human hair). It investigates new perspectives on the chemical, environmental, biomedical, electronics, automotive and aerospace industries at the Nano scale that have unique surface, catalytic and magnetic properties that were previously considered impossible.[4]

"Nano" prefix means part of a billion, or thousand million. Nanosecond is a time measurement unit equal to one thousand million seconds. Nanometer is a unit measuring the extreme lengths of microscopy that can only be knew, equal to one billion of meters [4]; [6]; [24].

Nano Science is a science that is interested in studying and characterizing nanomaterial's, identifying their chemical, physical and mechanical properties, while studying phenomena arising from their downsizing [4];[24].

Nanotechnology is the practical application of knowledge in a particular field at the Nano level. It is that technological capability that provides the possibility of synthesis of nanomaterial's, and control of their internal structure by restructuring and arranging their constituent atoms, ensuring access to unique products, employed in various applications. [4];[6];[12].

Nanotechnology interferes with most life activities and increases its quality. Its impact in the field of agricultural sciences is reflected in the improvement and development of agricultural tools and products, which yields rewarding returns, providing quality products and facilitating agricultural processes. [24].

The Nanotechnology has many applications in the field of food, as follows:[4];[25].

Add so-called food Nano sensors, which allow the average consumer to determine whether or not food is safe, by changing the color of the sensor if there are microorganisms harmful to food. 'Packaging materials were created using calcium silicate to mitigate the effect of air heat on food, especially during export. Color and taste molecules, when placed in the microwave at a certain frequency becomes lemon juice, and at another frequency becomes the same apple juice, and these species are called attractive foods, the reason for this is that these drinks contain thousands of Nano capsules containing flavour and color catalysts, and other additives released only at the consumer's will, where food changes according to need.

created the so-called Nanobot, which can collect steaks or flour from atoms: oxygen, carbon, and hydrogen in the air in the form of water or carbon dioxide. Nanobots are a food booster and booster and can move into blood vessels to clean fat deposits and contribute to the killing of pathogens.

Potato chip production companies are also competing to produce special varieties containing very small proportions of table salt, with the same taste as ordinary species with a natural salt content, due to the reduction of crystalline granules of cycloide (table salt) until their diameters reach about $10 \mathrm{~nm}$, increasing their sense of salty taste despite the low concentration of salt used .Following the same method as before, the sizes of sugar granules used in the manufacture of preserved and packaged sweets are reduced to the lowest extent, with the aim of producing special types of sweets suitable for diabetics or those who follow special food programs.

As there are many applications in agriculture for nanotechnology as follow:[1];[3];[16];[24].

Nanotechnology plays a leading role in agriculture by providing many nanomaterial's used as chemical fertilizers that increase plant growth, improve soil, positively reflect crop and crop quality, and increase agricultural area production. Nanotechnology is used in the manufacture of agrochemical granules used to control insects, fungi and agricultural pests affecting soils and 
plants, and seeds are characterized by the high value of their surface area, which means rationalizing their use and reducing the amounts used, thereby reducing the environmental impacts. Some companies produce Nano granules consisting of fertilizer chemicals added to pesticides, which are packaged together within those capsules; Nano food elements, both small and large, needed by the plant, such as potassium, nitrogen, iron, zinc, calcium and phosphate, have been produced, allowing them to be used in many field crops or horticultural crops, for example: Nano-calcium has been used to spray on grapes grown under salinity stress, resulting in increased concentration of chlorophyll in leaves and green growth.

Nanotechnologists have devised solutions to the problem of water loss, which amounts to 50\%inhightemperature areas, resulting in a rise in soil salinity, and thus reduced fertility, where they have come up with a unique method that reduces the speed of water flow to the soil and controls its surface flow rate in order to reduce its evaporation rates to the lowest possible extent, and this method depends on the use of zeolite metal to do this difficult task.

Nanotechnology has a role to play in fish farming and aquaculture, where fish farms suffer from outbreaks of certain diseases and increased chemical pollution in their waters. Researchers work in laboratories of one of the companies specialized in chemicals recently produced by the company for use in cleaning the water of fish farms, and this drug consists of nano granules of compounds and alloys of the element of (Lanthanum H A), which do not exceed the dimensions of its diameters 40 nanometers added in certain proportions to the waters of fish ponds. The results indicated that these granules have succeeded in ridding fish farm water of their phosphates, which is the main cause of algae growth in farm water.

Nano-devices are also used in what are known as smart delivery systems with distinct features to make agricultural systems intelligent, i.e. devices can be used to show the state of healthy plants and expected diseases, before appearing to the farmer himself, acting as a protective and warning, and there is the possibility of using them to deliver therapeutic chemicals in a controlled manner. Outputs, by monitoring climate variables, taking some necessary measures, using Nano sensor and control devices, distributed in agricultural fields to monitor the state of soil, chemicals, fertilizers, pests, pollutants, water use and climate measurement, to see if crops grow more efficiently, determine the nature of the local place and be linked to the problem system; and then address them, all of which will of course lead to significant productivity at low cost, reducing agricultural waste and polluting the environment.

Nanoparticles are divided into two types, the primary, Fixed Nanoparticles: molecules that are integrated into the material extract, the material itself, or even devices, such as nano-componences and Nano-surfaces. The second is Free Nanoparticles: individual nanoparticles of a substance, within the stages of the production and use process. There is a consensus that the current concern is free nanoparticles [24].

Nanoparticles differ significantly from their counterparts at the larger level, so their toxic effects such as large materials cannot be inferred, resulting in important issues to address the environmental and health impacts of free nanoparticles [24].

The researchers benefited from the previous detailed presentation and detailed review of literature and studies in the construction of the diagnostic interview form and the measure of the trend towards nanotechnology

\section{Methodology: \\ Participants}

The following tables present the data of the research sample in detail as follows:

Displays Table (1): number of the students in each discipline separately, and their gender.

The current Study relied on the use of the following two approaches:

Table (1): number of the students in each discipline

\begin{tabular}{lccc}
\hline \multirow{2}{*}{ Specialization } & \multicolumn{2}{c}{ Gender } & \multirow{2}{*}{ Total } \\
\cline { 2 - 3 } & Females & Males & \\
\hline Lab. Technician & 17 & 18 & 35 \\
$\begin{array}{l}\text { Food } \\
\text { manufacturing. }\end{array}$ & 17 & 18 & 35 \\
$\begin{array}{l}\text { Agricultural } \\
\text { mechanization }\end{array}$ & 16 & 19 & 35 \\
Total & 50 & 55 & 105 \\
\hline
\end{tabular}

\section{Data collection and survey instrument:}

To answer the research questions, data were collected from 105 students (table:1).The data was collected by a diagnostic interview form that includes a set of general questions about nanotechnology and its applications in agricultural and food sciences, in order to determine the research sample's knowledge of nanotechnology. The attitude of the students of the research sample towards nanotechnology was measured using the Attitude Scale towards Nanotechnology, which included 40 items, and in front of each item was a scale of rating (agree, neutral, disagree). This was applied between 10/26/2021 to 30/12/2021.

The study tools were presented to specialists in curricula and agricultural sciences teaching methods to ensure the validity of their content, and to determine the standard degree in the light of which the students' results will be interpreted. They indicated its credibility, and they agreed that the standard score should not be less than $60 \%$ of the total score of the tools. 
Table (3): The results of the knowledge of the sample students about nanotechnology.

\begin{tabular}{|c|c|c|c|c|c|c|}
\hline \multirow{2}{*}{$\begin{array}{l}\text { research } \\
\text { sample }\end{array}$} & \multirow{2}{*}{$\mathbf{N}$} & \multirow{2}{*}{$\begin{array}{c}\text { Mea } \\
\text { n }\end{array}$} & \multirow{2}{*}{$\begin{array}{c}\text { Std. } \\
\text { Deviation }\end{array}$} & \multirow{2}{*}{$\begin{array}{c}\text { Standard } \\
\text { mean }\end{array}$} & \multicolumn{2}{|c|}{$\begin{array}{c}\begin{array}{c}\text { Confidence } \\
\text { interval }\end{array} \\
\end{array}$} \\
\hline & & & & & Lower & Upper \\
\hline Lab. Tech. & 35 & 1.29 & 1.09 & 6 & .93 & 1.64 \\
\hline $\begin{array}{l}\text { Food } \\
\text {.manu. }\end{array}$ & 35 & 1.03 & 1.13 & 6 & .95 & \\
\hline $\begin{array}{l}\text { Agri. } \\
\text { Mech. }\end{array}$ & 35 & 1.34 & 1.17 & 6 & .62 & 1.43 \\
\hline $\begin{array}{l}\text { Total } \\
\text { sample }\end{array}$ & 105 & 1.21 & 1.11 & 6 & 1 & 1.43 \\
\hline
\end{tabular}

It is clear from the previous table that the total sample average is 1.21 compared to the standard average of 6 that there are significant differences between what students must have and what they actually have ; in order to be said to have Nano-knowledge. There were also no big differences related to the students' specializations. The laboratory technician students got an average of 1.29 , the food processing students got an average of 1.03, and the agricultural mechanization students got an average of 1.34 out of the standard average 6 . Looking at the confidence intervals for the total average of 1.21 for the research sample, it becomes clear that it ranges from 1 as a minimum to 1.43 as a maximum, which means that the total average falls within it, and this indicates that the general average of the research community falls within this range of the confidence interval. By comparing the averages of different disciplines with their confidence intervals, we find that they fall within them. This also means that the average of the population from which the samples were taken are within this range of confidence intervals.

Figure (1) presents a comparison between of the male and female sample in each discipline separately, to determine whether there are differences in their knowledge due to gender.

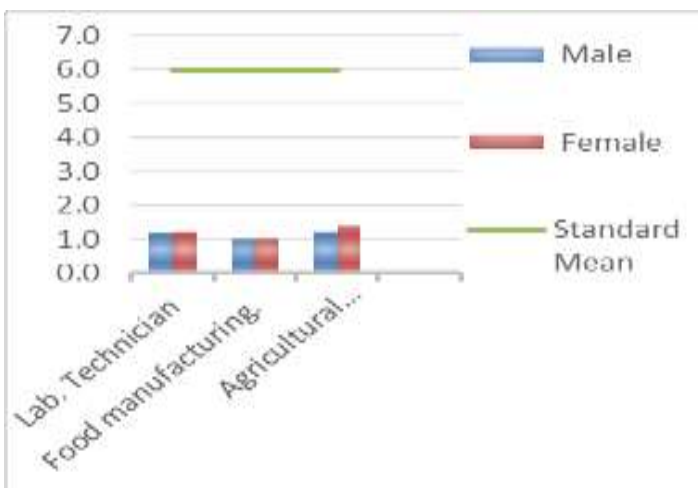

Figure (1) A comparison between the results of the knowledge of the male and female sample students about nanotechnology in each specialization with the standard mean.
The previous figure shows the low level of knowledge of the sample students, whether male or female, in nanotechnology and in various disciplines, as the female laboratory technician students got an average of 1.2 and the males got 1.2,and the sample students majoring in food processing got an average of 1 for females, and 1 for male, As well as it is clear that the students of agricultural mechanization specialization got an average of 1.2 for females, and males got 1.3 of the standard mean(6); That is, there is no big difference between males and females in different disciplines. In general, the low level of agricultural secondary school students' knowledge of nanotechnology and its applications in food and agriculture is evident.

\section{Secondly:}

Presentation and interpretation of data to answer the second question, which states: what is the degree of attitudes of agricultural secondary school students about nanotechnology and its applications in agriculture and foods in Egypt?

In order to answer the previous question, the scale in attitudes towards nanotechnology was applied to measure the attitudes towards nanotechnology on the sample students, and the results showed the following:

Table (4): The results of the sample students' attitudes towards nanotechnology

\begin{tabular}{|c|c|c|c|c|c|c|}
\hline \multirow[b]{2}{*}{$\begin{array}{c}\text { Research } \\
\text { sample }\end{array}$} & \multirow[b]{2}{*}{$\mathbf{N}$} & \multirow[b]{2}{*}{ Mean } & \multirow[b]{2}{*}{$\begin{array}{c}\text { Std. } \\
\text { Deviation }\end{array}$} & \multirow[b]{2}{*}{$\begin{array}{c}\text { Standard } \\
\text { mean }\end{array}$} & \multicolumn{2}{|c|}{$\begin{array}{c}\text { Confidence } \\
\text { interval }\end{array}$} \\
\hline & & & & & Lower & Upper \\
\hline \multirow[t]{2}{*}{ Lab. Tech. } & & & & & & 46.5 \\
\hline & 35 & 45.45 & 3.2 & 70 & 44.3 & \\
\hline \multirow[t]{2}{*}{ Food. Man. } & & & & & & 44.07 \\
\hline & 35 & 43.34 & 2.14 & 70 & 42.6 & \\
\hline \multirow[t]{2}{*}{ Agri. Mech. } & & & & & & 44.4 \\
\hline & 35 & 43.8 & 1.8 & 70 & 43.2 & \\
\hline \multirow[t]{2}{*}{ Total sample } & & & & & & 44.7 \\
\hline & $\begin{array}{l}10 \\
5\end{array}$ & 44.2 & 2.6 & 70 & 43.7 & \\
\hline
\end{tabular}

It is clear from the previous table that the total sample average is 44.2 compared to the standard average of 72 that there are big differences between what students must have and what they actually have; in order to be said to have attitude to nanotechnology. There were also no clear and big differences related to the students' specializations.it is nearly equal.

as the laboratory technician students got an average of 45.45 , the food processing students got an average of 43.43, and the agricultural mechanization students got an average of 43.8 out of the standard average 72 . Looking at the confidence intervals for the total average of 44.2 for the research sample, it becomes clear that it ranges 
from 43.7 as a minimum to 44.7 as a maximum, which means that the total average falls within it, and this indicates that the general average of the research community falls within this range of the confidence interval. By comparing the averages of different disciplines with their confidence intervals, we find that they fall within them. This also means that the average of the population from which the samples were taken are within this range of confidence intervals. Figure (2) presents a comparison between of the male and female sample in each discipline separately, to determine whether there are differences in their attitudes due to gender.

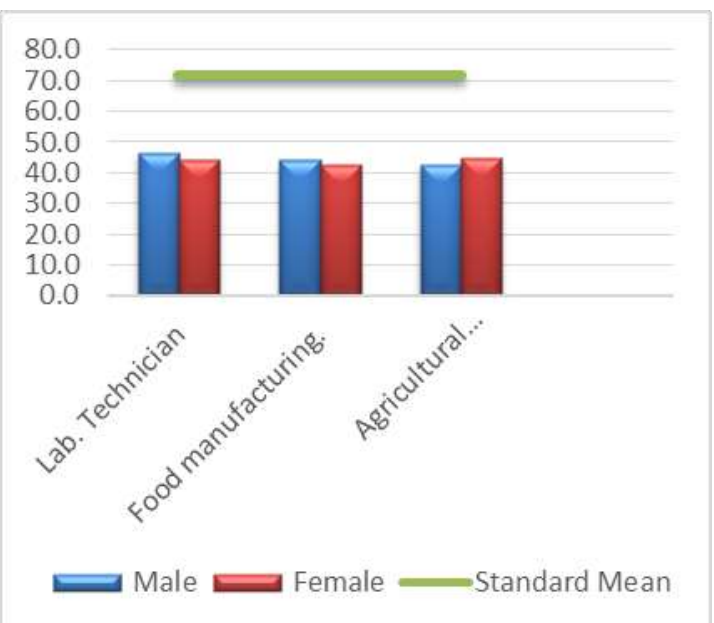

Figure (2) a comparison between of attitudes of the male and female sample about nanotechnology in each specialization with the standard mean.

It is clear from the previous figure that the students of the agricultural mechanization obtained an average score of(42.9) for males and (44.7) for females, and food processing students 44 for males and 42.8 for females, and laboratory technician students also got 46.5 for males and 44.4 for females compared with standard mean 72 is low level ; at the same time no big differences between the males and females overall due to the gender. In general, the low level of agricultural secondary school students' attitudes to nanotechnology and its applications in food and agriculture is evident.

\section{Thirdly:}

Presentation and interpretation of data to answer the third question, which states: is there a correlation between agricultural secondary school students' knowledge of nanotechnology and its applications in agriculture and food and their attitudes towards it?

To answer the previous question, it was necessary to find a Pearson correlation between the level of knowledge of the sample students about nanotechnology and their attitudes towards it.
Table (4): Pearson's correlation coefficient between the sample students' knowledge of nanotechnology and their attitudes towards it.

\begin{tabular}{llll}
\hline \multicolumn{1}{c}{ The variables } & \multicolumn{1}{c}{ Their } \\
knowledge & $\begin{array}{c}\text { Their } \\
\text { attitudes }\end{array}$ \\
\hline Their knowledge & Pearson & 1 & $.926^{* *}$ \\
& Correlation & & .000 \\
& Sig. (2-tailed) & 105 & 105 \\
& $\mathrm{~N}$ & 105 & 1 \\
Their attitudes & Pearson & $.926^{* *}$ & \\
& Correlation & & \\
& Sig. (2-tailed) & .000 & 105 \\
\hline & $\mathrm{N}$ & 105 & \\
\hline
\end{tabular}

**. Correlation is significant at the 0.01 level (2-tailed). It is clear from Table (4) that there is a strong positive correlation between the level of students' knowledge of nanotechnology and their attitudes towards it.

\section{Discussing}

It is clear from the presentation of the data that agricultural secondary school students in Egypt totally have no knowledge about nanotechnology, and therefore their tendency towards nanotechnology is low. as that there is a high correlation between the student's knowledge and their attitudes towards nanotechnology. These results are consistent with the results of a Vandermoere, et.al. (2010) study conducted in Germany, where the study showed that most people have apathy or a severe lack of awareness of nanotechnology. Many surveys have shown that most of the public has little or no awareness of nanotechnology. In an online study conducted by Kahan et al. (2007) With 1,850 Americans participating, $81 \%$ of participants said they had not heard of nanotechnology. A study conducted by Waldron et al.(2006) of the 1,500 participants between the ages of 6 and $74,60 \%$ revealed that $60 \%$ had not heard of nanotechnology. They reported that the general public, especially high school students, has very limited knowledge of nanotechnology. A study conducted by Macoubrie (2006) to develop the positions and opinions of U.S. citizens on nanotechnology development revealed that $95 \%(n=152)$ of participants had not heard of nanotechnology before being informed of it in the context of a study. A recent study conducted in Iran showed that most people are still not familiar with nanotechnology, but those who were aware of its benefits outweigh the risks (Freschi et al. 2011).

This is due to the lack of nanotechnology concepts and applications in curricula, as well as the lack of interest of officials in developing the curriculum according to modern techniques. Moreover, media 
organizations do not play their role in educating the community about modern technologies such as nanotechnology, its applications, benefits, and damages.

\section{Recommendation}

We are recommended the following:

- Including the concepts and applications of nanotechnology in agricultural high school curricula.

- The establishment of advanced nanotechnology plants in agricultural secondary schools.

- Educating agricultural science teachers about the concepts and applications of nanotechnology

\section{Conclusion and further studies}

This study aimed to determine the knowledge and attitudes of agricultural high school students about nanotechnology and its applications, taking into account the student's gender, and his exact specialization.

The results showed a low level of student's knowledge about nanotechnology, as well as their attitudes towards it. It also showed a strong relationship between students' low knowledge and their low attitudes towards nanotechnology. also, there is no difference in the knowledge and attitudes of students regarding gender or specialization

\section{Further studies}

- Conducting a study aimed at raising the level of nanotechnology awareness among agricultural secondary school students.

- Conducting a study aimed at evaluating the level of Egyptian society's awareness of the benefits and risks of nanotechnology.

- Conducting a study aimed at measuring the awareness of agricultural science teachers about nanotechnology and its applications.

1) Reconsider the success rate (30\%) set by the Ministry in the list used and increase it.

\section{Acknowledgment}

We are pleased to thank everyone who cooperated with us at any stage of the research, and we mention Mohamed Mounir Abdel-Fattah, "Demonstrator of Agricultural Education", Faculty of Education - Tanta University, and the student-teachers specializing in agricultural sciences Senior 2019.

\section{References}

[1] Al-Dawyan,A; al-Salhi,M. (2007). Introduction to nanotechnology. Riyadh: King Saud University.

[2] Alford, K. Farokzal, C. ; Langer, R. (2007). An Integrated Industry Linked Approach To Develop. Nanotechnology Curriculum For Secondary Students In Australia, Brides. (1), 631- 634.

[3] Al-Habshi,N. (2011). What is nanotechnology: a brief introduction in the form of simplified lessons? Riyadh, Al-Abkian.
[4] Al-Iskandrani,M. (2010) .Nanotechnology for a better tomorrow. Kuwait, world of knowledge..

[5] Andrew, S. Et Al., (2011). "Welcome To Nano Science: Interdisciplinary Environmental Exploration, Grades 9-12" .National Science Teachers Association.

[6] Bassiouni,A. (2008). Nanotechnology concepts. Cairo: Scientific Book House for Publishing and Distribution.

[7] Burri, R. V., \& Bellucci, S. (2008). Public perception of nanotechnology. Journal of Nanoparticle Research.10(3), 387-391.

[8] Cobb, M. D. (2005). Framing effects on public opinion about nanotechnology. Science Communication, 27(2), 221-239.

[9] Ekli, E., \& Şahin, N. (2010). Science teachers and teacher candidates' basic knowledge, opinions and risk perceptions about nanotechnology. Procedia Social and Behavioral Sciences, 2, 2667- 2670.

[10] Farshchi, P., Sadrnezhaad, S. K., Nejad, N. M., Mahmoodi, M., \& Abadi, L. I. G. (2011). Nanotechnology in the public eye: The case of Iran, as a developing country. Journal of Nanoparticle Research, 13(8), 3511-3519.

[11] Foltz,F.(2005). The Societal And Ethical Implications Of Nanotechnology: A Christian Response. The Journal Of Technology Studies. 104114.

[12] Halawa,M. (2010). Towards new nanoconcepts, nanometerology is an imperative necessity for nanotechnology. Cairo: National Institute of Measurement and Standards.

[13] Healy, N.(2009): Why Nano Technology ? . Journal Of Nano Education. (1), 6-7.

[14] Hijazi,A. (2012). Nanotechnology: The New Technological Revolution. Jordan: Treasures of Knowledge Publishing and Distribution.

[15] Hingant, B. ; Albe, V. (2009). "Nano Science And Technologies Learning And Teaching In Secondary Education" EBISCO. (46), 121- 152.

[16] Hussein,S; al-Sayed,A; and Ahmed,A. (2018). Nanotechnology and its applications in the agricultural and food field and its implications for the future" Arab Foundation for Scientific Research and Human Development. 11, 66-58.

[17] Kahan, D. M. (2009). Nanotechnology and society: The evolution of risk perceptions. Nat. Nanotechnol. 4, 705-6.

[18] Kahan, D. M., Slovic, P., Braman, D., Gastil, J., \& Cohen, G. (2007). Nanotechnology risk perceptions: The influence of affect and values. Cultural Cognition Project at Yale Law School http://www. nanotechproject.org/file_download/files/NanotechRi skPerceptions- DanKahan.pdf. Accessed 7 August 2012.

[19] Laherto, A. (2010). An Analysis of the educational significance of nanoscience and nanotechnology in scientific and technological literacy. Science Education International, 21(3), 160-175. 
[20] Lakin ,J; Hani,Y; Davis,G.(2016).First- Years Student's Attitudes Towards The Grand Challenges And Nanotechnology. Journals of Stem Education. (17)3, 70- 76 .

[21] Macoubrie, J. (2006). Nanotechnology: Public concerns, reasoning and trust in government. Public Understanding of Science, 15(2), 221-241.

[22] Roco, M. C., \& Bainbridge, W. S. (2005). Societal implications of nanoscience and nanotechnology:Maximizing human benefit. Journal of Nanoparticle Research, 7(1), 1-13.

[23] Salama,S. (2009). Nanotechnology is a small world and a great future. Beirut: Arab House of Sciences publishers.

[24] Saleh,M. (2015). Nanotechnology and a new scientific age.,Saudi Arabia, indexing the King Fahd National Library during publication, Riyadh, King Abdulaziz City of Science and Technology.

[25] Shain , N; Ekli, E. (2013). Nanotechnology Awareness, Opinions And Risks Perception Among Middle School Students. Springer Science.(23),867881.

[26] Toqeer Ahmed, Saba Imdad, Khwaja Yaldram, and Syed Mohsin Raza(2015).Awareness and Attitude About Nanotechnology in Pakistan. Journal of Nano Education Vol. 7, 44-51, 2015

[27] Vandermoere, F., Blanchemanche, S., Bieberstein, A., Marette, S., \& Roosen, J. (2010). The morality of attitudes toward nanotechnology: About God, techno-scientific progress, and interfering with nature. Journal of Nanoparticle Research, 12(2), 373-381.

[28] Waldron, A. M., Spencer, D., \& Batt, C. A. (2006). The current state of public understanding of nanotechnology. Journal of Nanoparticle Research, 8(5), 569-575.

[29] Yolcu, H. (2018). Engineering Major Student's Perceptions Of Nanotechnology. International Journal Of Progressive Education. 14(4), 37-51.

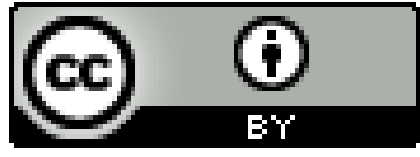

